\title{
Effect of SNX-2112 on proliferation of esophageal cancer cells via regulation of excision repair cross-complementing 1 , epidermal growth factor receptor, and p53 expression
}

\author{
C.Y. Li ${ }^{1}$, Y.J. Ren ${ }^{2}$ and Y.D. $\mathbf{L i}^{3}$ \\ ${ }^{1}$ Department of Gastroenterology, \\ Yantai Liu Huangding Affiliated Hospital of Qingdao University, \\ Shandong, China \\ ${ }^{2}$ Department of Emergency Medical Center, \\ Yantai Liu Huangding Affiliated Hospital of Qingdao University, \\ Shandong, China \\ ${ }^{3}$ Department of Blood Nephrology, Wendeng Municipal Hospital, \\ Shandong Province, China \\ Corresponding author: Y.D. Li \\ E-mail: liyaodong1357@163.com \\ Genet. Mol. Res. 15 (2): gmr.15028318 \\ Received March 7, 2016 \\ Accepted April 11, 2016 \\ Published June 24, 2016 \\ DOI http://dx.doi.org/10.4238/gmr.15028318
}

\begin{abstract}
SNX-2112 is a potential molecular targeted therapeutic drug against esophageal cancer (EC). However, its exact mechanism of action remains to be explained. The aim of this study was to investigate the effect of SNX-2112 on excision repair cross- complementing 1 (ERCC1), epidermal growth factor receptor (EGFR), and p53, to elucidate the mechanism of action of SNX-2112 on EC. Fresh tumor sections were surgically obtained from 65 patients with EC, and the expression of ERCC1, EGFR, and p53 was determined by immunohistochemical staining. Furthermore, the effect of SNX-2112 $(0.2 \mu \mathrm{M})$ on the proliferation of EC-9706 cells and the expression
\end{abstract}


of ERCC1, EGFR, and p53 in these cells were analyzed by a cell proliferation assay and western blot, respectively. We observed a significant decrease and increase in ERCC1 $(\mathrm{P}=0.001)$ and p53 $(\mathrm{P}=$ 0.043 ) expression, respectively, and no significant difference in EGFR $(\mathrm{P}=0.59)$ expression, with the TNM stage of EC, which suggested that ERCC1 and p53 could be potential markers for the TNM stage of EC. We also observed a significant increase in ERCC1 expression, and decrease in p53 and EGFR expression, in EC-9706 cells treated with SNX-2112 $(\mathrm{P}<0.05)$, indicating the regulation of EC by SNX-2112. Furthermore, SNX-2112 treatment induced a significant decrease in the proliferation of EC-9706, which confirmed the function of SNX2112. In summary, SNX-2112 inhibits the proliferation of EC cells by regulating the expression of ERCC1, EGFR, and p53.

Key words: Esophageal cancer; SNX-2112; ERCC1; EGFR; p53; EC-9706 cells

\section{INTRODUCTION}

Esophageal cancer (EC) has the second highest mortality rate among gastrointestinal cancers (Mohamed et al., 2014). The "esophageal cancer belt", comprising Asia, Africa, and Iran, has the highest incidence rate of EC in the world (Kaz and Grady, 2014). Radiotherapy and chemotherapy are the major surgical intervention techniques for EC. However, the traditional chemo-radiotherapeutic approaches are toxic and of limited efficacy, and therefore do not satisfy the clinical requirements for cancer treatment (Chen et al., 2011). Recently, molecular analyses of cancer cells have uncovered key genetic and epigenetic alterations underlying the occurrence and development of tumors, which has in turn paved the way for molecular targeted therapy of cancer (Belkhiri and El-Rifai, 2015). Molecular targeted therapy, considered to be more effective and less harmful to normal cells than traditional forms of treatment, is one of the major modalities of cancer pharmacotherapy. Molecular targeted therapy could block the growth of cancer cells by interfering with specific molecules that induce or affect carcinogenesis and tumor growth (Holohan et al., 2013), as opposed to interfering with all rapidly dividing cells as with traditional chemotherapy.

Heat shock protein 90 (Hsp90) plays a pivotal role in guiding the normal folding and proteolytic turnover of many key regulators of cell growth, differentiation, and survival (Chen et al., 2014). Hsp90 regulates several signal transducing molecules, such as protein kinases and steroid hormone receptors (Taipale et al., 2012). This essential guardian function of Hsp90 is subverted during oncogenesis, allowing for malignant transformation and facilitating rapid somatic evolution. The use of Hsp90 as a target in molecular therapy could be a unique anticancer strategy of considerable promise.

Hsp90 inhibitors are responsible for the destabilization, and consequently, degradation, of Hsp90 client proteins, by interacting specifically with a single molecular target. Additionally, they have shown promising antitumor activity in preclinical model systems (Hall et al., 2014). Recent studies have reported a novel small molecule class of Hsp90 inhibitors that are exemplified by SNX-2112, which competitively binds to the N-terminal adenosine triphosphate binding site of Hsp90. SNX-2112 induces the degradation of multiple Hsp90 
client proteins and activates both the mitochondrial-mediated and death receptor-mediated apoptotic pathways (Liu et al., 2015).

Excision repair cross-complementing 1 (ERCC1) plays a major role in the nucleotide excision repair pathway, and is required for the repair of DNA lesions, such as those induced by UV light or formed by electrophilic compounds like cisplatin (Calderón-Montaño et al., 2014). ERCC1 serves as an important DNA excision repair protein and is reported to be associated with tumor development (Goldstein and Kastan, 2015). Epidermal growth factor receptor (EFGR), which is present on the cell surface, is activated by binding of its specific growth factor ligands. Upon activation, EGFR undergoes transition from an inactive monomeric form to an active homo-dimeric form, which contributes to cell signaling in diverse cellular functions, including cell proliferation, differentiation, motility, and survival (Avraham and Yarden, 2011). Mutations that lead to EGFR overexpression have been associated with a number of cancers. These somatic mutations involving EGFR lead to its constant activation, which in turn is responsible for uncontrolled cell division (Zhen et al., 2014). p53 has been described as "the guardian of the genome" because of its role in conserving stability by preventing genome mutation (Lopez-Serra and Esteller, 2012). The $p 53$ gene plays a crucial role in preventing cancer formation.

SNX-2112 is a potential therapeutic agent for EC; moreover, Hsp90 inhibitors are confirmed to be associated with ERCC1 (Tsai et al., 2012), EGFR (Johnson et al., 2015), and p53 (Li et al., 2013). However, to the best of our knowledge, the exact mechanisms of SNX2112 have not been elucidated, and the efficacy of SNX-2112 in EC has not been assessed based on its expression.

The aim of this study was to confirm the association between the clinicopathological characteristics of EC and the expression of ERCC1, EGFR, and p53, and determine the prognostic implications of these factors in EC. ERCC1, EGFR, and p53 expression in EC9706 cells was analyzed before and after the SNX-2112 treatment, in order to explain the possible effect of SNX-2112 on EC.

\section{MATERIAL AND METHODS}

\section{Patients}

This study was approved by the Scientific Ethics Committee of Yantai Liu Huangding Affiliated Hospital at Qingdao University; informed consent was obtained from all patients prior to the study. Sixty-five subjects (average age: $62.46 \pm 2.5$ years) from 23 Chinese cities diagnosed with EC at our hospital between January 2012 and June 2014 were recruited in this study. The included patients were not subjected to preoperative radiotherapy and/ or chemotherapy. EC was confirmed in all patients via a histopathological analysis and a gastroscopy. The cancer stage was determined according to the amount of tumor invasion (T), involvement of lymph nodes (N), and distant metastasis (M) (TNM staging system) (Pennathur et al., 2013). Integrated clinical data, including the age, gender, tumor length, and invasion depth, were collected and have been summarized in Table 1; additionally, data regarding other demographic characteristics not included in this study were obtained from all patients.

\section{Chemicals and reagents}

The Hsp90 inhibitor SNX-2112, provided by Serenex (Durham, NC, USA), was 
dissolved in dimethyl sulfoxide (DMSO) to a stock concentration of $50 \mathrm{mg} / \mathrm{mL}$ and stored at $-20^{\circ} \mathrm{C}$ for in vitro analyses. EC-9706 cells cultured in fresh medium were treated with $0.2 \mu \mathrm{M}$ SNX-2112 for 2 days.

\section{Cell culture}

EC-9706 cells were incubated in RPMI 1640 supplemented with $100 \mathrm{~mL} / \mathrm{L}$ fetal bovine serum, $100 \mathrm{kU} / \mathrm{L}$ penicillin, $100 \mathrm{mg} / \mathrm{L}$ streptomycin, and $2 \mathrm{mM} \mathrm{L}$-glutamine in a 50$\mathrm{mL} / \mathrm{L} \mathrm{CO}_{2}$ humidified incubator at $37^{\circ} \mathrm{C}$.

\section{Immunohistochemical staining}

Fresh tumor samples were obtained from the patients via surgery and were fixed immediately in $4 \%$ neutral buffered formalin. Fixed tissues were dehydrated in ethanol and embedded in paraffin blocks. Sections ( $4 \mathrm{~mm}$ ) of methacarn-fixed tissues were cut using a microtome (Leica, Oberkochen, Germany) and air-dried on poly-L-lysine-coated slides; these were dewaxed with xylene, dehydrated with ethanol, and treated with $3 \% \mathrm{H}_{2} \mathrm{O}_{2}$ at $37^{\circ} \mathrm{C}$ for $10 \mathrm{~min}$. The sections were then thoroughly rinsed with phosphate-buffered saline (PBS) three times. Subsequently, the sections were placed in Coplin jars containing citric acid buffer, $\mathrm{pH}=6.0$, and heated in a microwave for $15 \mathrm{~min}$ (three 5-min cycles with an interval of $1 \mathrm{~min}$ between cycles). The jars were then allowed to cool for $20 \mathrm{~min}$ at room temperature. The sections were then rinsed three times in PBS for 5 min each. The sections were blocked with goat serum for 10 min at $37^{\circ} \mathrm{C}$, excess serum was removed, and the sections were incubated overnight with the primary antibody at $4^{\circ} \mathrm{C}$. In each case, a corresponding section was incubated in PBS without the primary antibody for nonspecific staining (control). The sections were then incubated with a biotinylated secondary antibody at $37^{\circ} \mathrm{C}$ for $30 \mathrm{~min}$, and subsequently with a peroxidase substrate streptavidin-biotin complex at $37^{\circ} \mathrm{C}$ for $30 \mathrm{~min}$. The samples were thoroughly rinsed with PBS and immunostained with $\mathrm{DAB} / \mathrm{H}_{2} \mathrm{O}_{2}$. Finally, the sections were counterstained with hematoxylin and mounted with an aqueous mounting medium onto a coverslip; the sections were then observed using a microscope (Olympus, Tokyo, Japan). The control sections were incubated with an equal volume of saline instead of the primary antibody. Ten parallel experiments were conducted for each tumor sample and control group, and each independent group was analyzed in triplicate.

\section{Positive criteria for immumohistochemical staining}

The samples were classified into four different stages: non-staining (-), light yellow $(+)$, brownish-yellow $(++)$, and dark brown $(+++)$ staining, based on the degree of immunohistochemical staining. The samples were then observed under a microscope (400X), and labeled according to the proportion of stained cells as $<10 \%(-), 11-50 \%(+), 51-80 \%$ $(++)$, and $>80 \%(+++)$. The scores $(-),(+),(++),(+++)$ were designated as $1,2,3$, and 4 , respectively. The sum of the two scores was set as the positive criterion; that is, groups with a total score of $>4$ were considered to be positive (Figure 1).

\section{Cell proliferation assay}

A standard CCK-8 assay kit (Beyotime Biotechnology, Beijing, China) was used to 
analyze the proliferation of EC-9706 cells. Cells $\left(1 \times 10^{5}\right)$ were seeded into each well of a 96-well plate and cultured for $24 \mathrm{~h}$. The cells were then treated with SNX-2112 or DMSO (control) and incubated for $0,12,24,36$, and $48 \mathrm{~h}$. Subsequently, $10 \mu \mathrm{L}$ CCK-8 was added to each well and the plate was re-incubated for $1 \mathrm{~h}$. The absorbance at $450 \mathrm{~nm}$ of each well was detected. Cell proliferation in each group was measured in five wells, and each independent group was analyzed in triplicate.

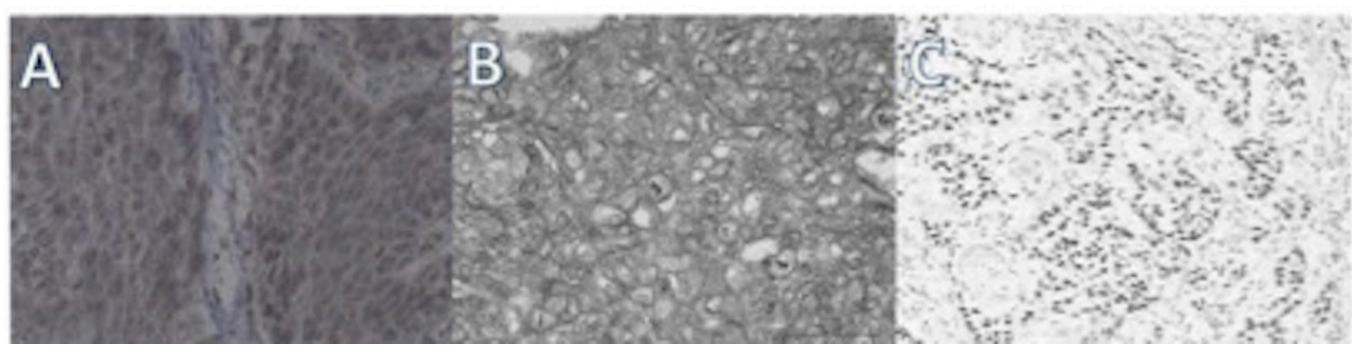

Figure 1. Representative expression of (A) ERCC1, (B) EGFR, and (C) p53.

\section{Western blot assay}

Total protein was isolated from cells using the cell extraction buffer (Biosource, Camarillo, CA, USA) supplemented with protease and phosphatase inhibitors. Total protein was pre-cleared by centrifugation and the protein concentration was measured using a standard bicinchoninic acid protein assay kit (Pierce, Rockford, IL, USA). The primary antibodies used in this study (including those against $\beta$-actin, ERCC1, EGFR, and p53) were purchased from Abcam (Cambridge, UK). Equal protein loading was confirmed by probing for $\beta$-actin expression. The cells were then incubated with anti-mouse or antirabbit immunoglobulin G (IgG; GE Healthcare, Little Chalfont, UK) secondary antibodies conjugated to horseradish peroxidase. The proteins were then visualized using an Amersham Enhanced Chemiluminescence detector (GE Healthcare).

\section{Statistical analysis}

All data were estimated according to the results of ten independent experiments. Statistical analysis was performed using the SPSS software platform (version 20.0; SPSS Inc., Chicago, IL, USA). Data were compared using the chi-square test; associations between the factors were determined by Spearman correlation. $\mathrm{P}<0.05$ was considered to be statistically significant.

\section{RESULTS}

\section{Association between ERCC1, EGFR, and p53 expression and clinicopathological characteristics of EC}

The effect of ERCC1, EGFR, and p53 on EC was confirmed by recording the clinico- 
pathological characteristics of patients; among these, the age, gender, tumor length, invasion depth, G staging, and TNM stage of all patients are summarized in Table 1. The expression of ERCC1, EGFR, and p53 was detected by immunohistochemical staining. We observed no significant association of ERCC1, EGFR, and p53 expression with patient age and gender or with tumor length and invasion depth. Additionally, we observed a significant decrease and increase in the expression of ERCC1 and p53, respectively, with the TNM stage of EC, which suggested ERCC1 and p53 as potential markers for the TNM stage of EC. EGFR overexpression was suggested to be associated with a number of cancers (Bastid, 2012); however, in this study, the expression of EGFR did not increase significantly with the TNM stage of EC, which suggested that the mechanisms of EC were unique, and that EGFR might be a key factor affecting this variation (Table 1).

Table 1. Data for 65 esophageal cancer patients [N (\%)].

\begin{tabular}{|c|c|c|c|c|c|c|c|c|c|c|}
\hline \multirow[t]{2}{*}{ Categories } & \multirow[t]{2}{*}{ Number } & \multicolumn{3}{|c|}{ ERCC1 } & \multicolumn{3}{|c|}{ EGFR } & \multicolumn{3}{|c|}{ p53 } \\
\hline & & Positive & Negative & $\mathrm{P}$ & Positive & Negative & $\mathrm{P}$ & Positive & Negative & $\mathrm{P}$ \\
\hline \multicolumn{11}{|l|}{ Age (years) } \\
\hline$\leq 60$ & 17 & $6(35.29)$ & $11(64.71)$ & 0.871 & $11(64.71)$ & $6(35.29)$ & 0.871 & $11(64.71)$ & $6(35.29)$ & 0.755 \\
\hline$>60$ & 48 & $18(37.50)$ & $30(62.50)$ & & $30(62.50)$ & $18(37.50)$ & & $29(60.42)$ & $19(39.58)$ & \\
\hline \multicolumn{11}{|l|}{ Gender } \\
\hline Male & 49 & $17(34.69)$ & $32(65.31)$ & 0.23 & $32(65.31)$ & $17(34.69)$ & 0.515 & $32(65.31)$ & $17(34.70)$ & 0.275 \\
\hline Female & 16 & $3(18.75)$ & $13(81.25)$ & & $9(56.25)$ & $7(43.75)$ & & $8(50.00)$ & $8(50.00)$ & \\
\hline \multicolumn{11}{|c|}{ Tumor length $(\mathrm{cm})$} \\
\hline$\leq 3$ & 20 & $9(45.00)$ & $11(55.00)$ & 0.097 & $15(75.00)$ & $5(25.00)$ & 0.184 & $14(70.00)$ & $6(30.00)$ & 0.35 \\
\hline$>3$ & 45 & $11(24.44)$ & $34(75.56)$ & & $26(57.78)$ & $19(42.22)$ & & $26(57.78)$ & $19(42.22)$ & \\
\hline \multicolumn{11}{|l|}{ G stage } \\
\hline G1 & 35 & $16(45.71)$ & $19(54.29)$ & 0.017 & $20(57.14)$ & $15(42.86)$ & 0.11 & $16(45.71)$ & $19(54.29)$ & 0.012 \\
\hline G2 & 19 & $3(15.79)$ & $16(84.21)$ & & $11(57.89)$ & $8(42.11)$ & & $14(73.68)$ & $5(26.32)$ & \\
\hline G3 & 11 & $1(9.09)$ & $10(90.91)$ & & $10(90.91)$ & $1(9.09)$ & & $10(90.91)$ & $1(9.09)$ & \\
\hline \multicolumn{11}{|c|}{ Invasion depth } \\
\hline $\mathrm{T} 1$ & 28 & $13(46.43)$ & $15(53.57)$ & 0.053 & $18(64.29)$ & $10(35.71)$ & 0.482 & $15(53.57)$ & $13(46.43)$ & 0.119 \\
\hline $\mathrm{T} 2, \mathrm{~T} 3$ & 23 & $5(21.74)$ & $18(78.26)$ & & $16(69.57)$ & $7(30.43)$ & & $18(78.26)$ & $5(21.74)$ & \\
\hline $\mathrm{T} 4$ & 14 & $2(14.29)$ & $12(85.71)$ & & $7(50.00)$ & $7(50.00)$ & & $7(50.00)$ & $7(50.00)$ & \\
\hline \multicolumn{11}{|l|}{ TNM stage } \\
\hline I & 16 & $7(43.75)$ & $9(56.25)$ & 0.001 & $10(62.50)$ & $6(37.50)$ & 0.59 & $7(43.75)$ & $9(56.25)$ & 0.043 \\
\hline II & 21 & $11(52.38)$ & $10(47.62)$ & & $15(71.43)$ & $6(28.57)$ & & $11(52.38)$ & $10(47.61)$ & \\
\hline III and IV & 28 & $2(7.14)$ & $26(92.86)$ & & $16(57.14)$ & $12(42.86)$ & & $22(78.57)$ & $6(21.43)$ & \\
\hline
\end{tabular}

\section{SNX-2112 inhibits the proliferation of EC cells by regulating the expression of ERCC1, EGFR, and p53}

The mechanism of SNX-2112 on the effect of ERCC1, EGFR, and p53 in EC was investigated by treating the EC-9706 cells with $0.2 \mu \mathrm{M}$ SNX-2112. The cell proliferation assay showed that the proliferation of EC-9706 cells was inhibited significantly by SNX2112 (Figure 2). Furthermore, western blot (Figure 3) showed that the application of SNX2112 resulted in increased ERCC1 expression, and significantly decreased p53 and EGFR expression $(\mathrm{P}<0.05)$, which indicated that $\mathrm{SNX}-2112$ was responsible for the regulation of ERCC1, EGFR, and p53 in EC. 


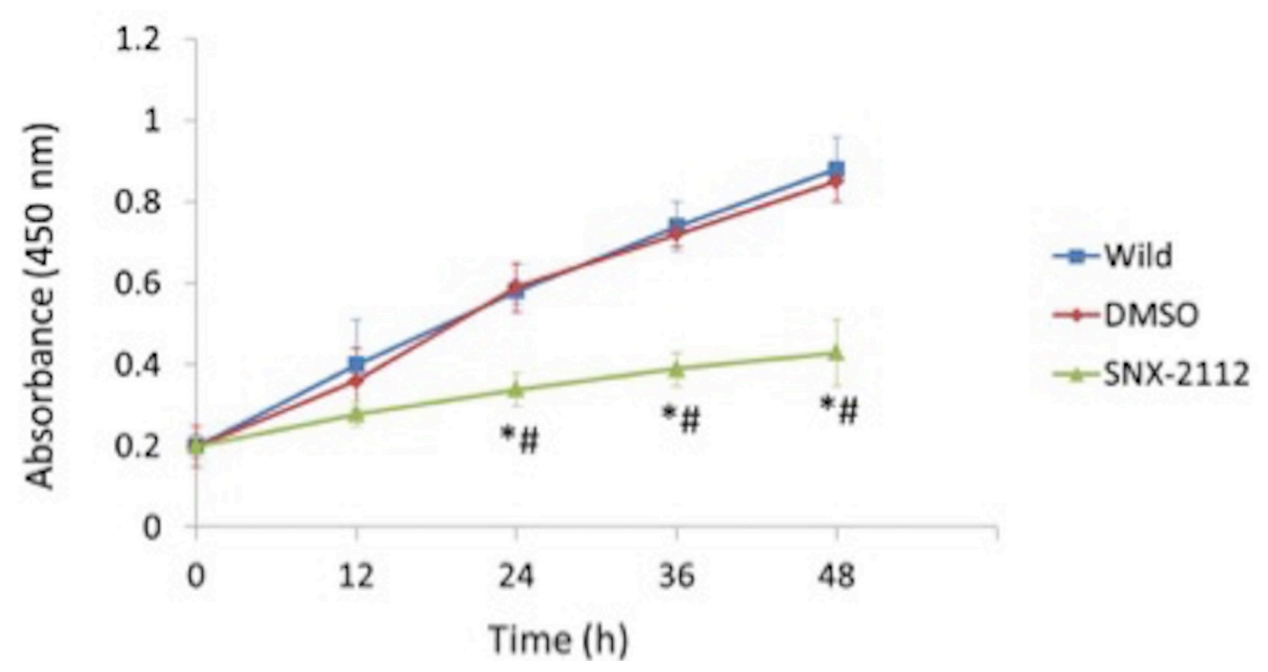

Figure 2. SNX-2112 inhibits the proliferation of EC-9706 cells. Proliferation of EC-9706 cells was evaluated after the application of 1) no solution (control group); 2) DMSO (DMSO group); and 3) SNX-2112 (SNX-2112 group). $* \mathrm{P}<0.05$ compared to the wild-type group. ${ }^{*} \mathrm{P}<0.05$ compared to the DMSO group.
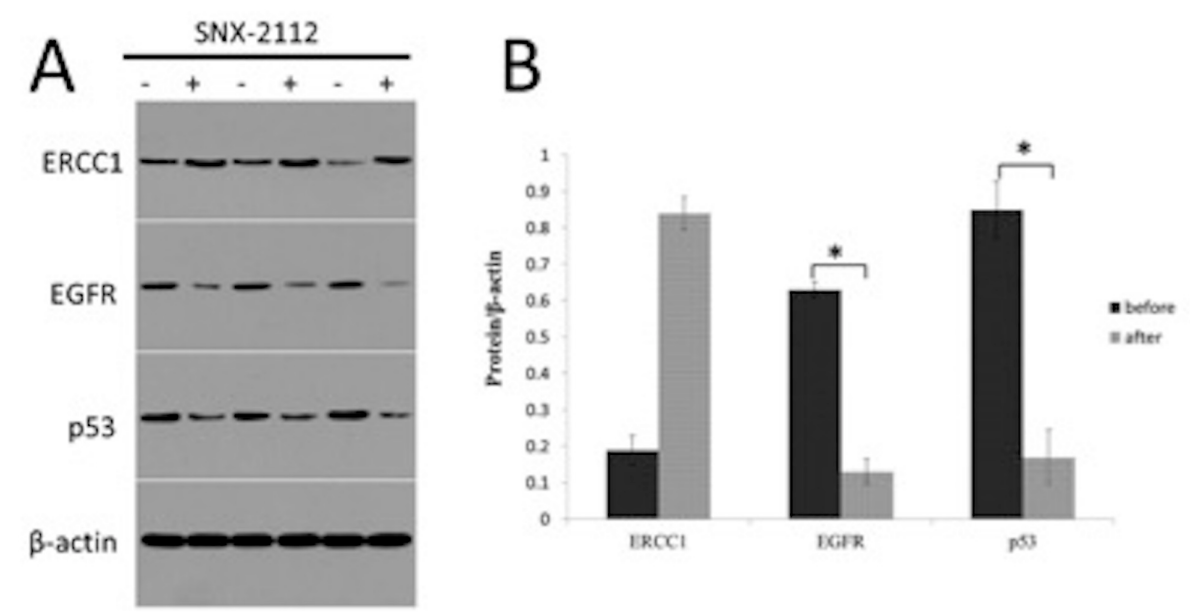

Figure 3. SNX-2112 regulates the expression of ERCC1, EGFR, and p53 in EC-9706 cells. The black columns (before group) comprise of EC-9706 cells before the application of SNX-2112 and gray columns (after group) comprise cells analyzed after the application of SNX-2112. $* \mathrm{P}<0.05$.

\section{DISCUSSION}

Recent years have seen advances in research on tumor pathology at a molecular level. These analyses have indicated that tumor development is a result of the interaction between proto-oncogenes and anti-oncogenes; moreover, multiple genes are reported to be involved in the occurrence and development of tumors (Rivlin et al., 2011). EC is one of the most common types of malignant tumors, whose exact mechanism, however, remains unexplained. Therefore, 
research on EC at the molecular level could help identify the key genes or markers for accurate and early diagnosis and treatment of EC, in turn providing novel methods for clinical practice.

DNA repair is important for maintaining normal cellular functions. Genetic variants of DNA repair genes and reduced DNA repair capacity are believed to contribute to increased susceptibility to cancer (Tong et al., 2009). ERCC1 plays a pivotal role in several DNA repair pathways and also forms a structure-specific heterodimeric endonuclease with xeroderma pigmentosum complementation group F, which cleaves damaged 5'-DNA in the lesion (Doll et al., 2010). Previous research has shown a strong association between the decrease in ERCC1 expression and the occurrence of cancer (Fan et al., 2011). The results of our study indicated that low ERCC1 expression was correlated with poor prognosis of EC, and SNX-2112 could be used to treat EC by increasing the expression of ERCC1. Interestingly, some researchers have suggested that patients who had advanced EC and also showed low expression of ERCC1 displayed improved response to preoperative chemo-radiotherapy. Additionally, preoperative chemo-radiotherapy may be more effective than immediate surgery in patients with low ERCC1 expression (Kim et al., 2008). Although the results of our study suggested that SNX2112 played an important role in DNA repair through regulating the expression of ERCC1, its exact influence on the overall survival and mechanism of EC needs to be investigated further.

Generally, EGFR exerts a signal transducing effect on the growth of cells, thereby regulating the growth, proliferation, and differentiation of cells (Worster et al., 2012). EGFR overexpression, caused by gene mutations, could also result in abnormal signal transduction and cell growth, leading to carcinogenesis (Rahman et al., 2014). Therefore, increased EGFR expression is a strong prognostic feature of multiple tumor types, and EGFR inhibition could have substantial therapeutic benefits. The results of this study suggested that the expression of EGFR could increase with the occurrence and development of EC, suggesting a positive correlation between the expression of EGFR and development of EC; although this association was not significant, it still indicated that EGFR could promote growth and metastasis in EC. Additionally, EGFR is an oncogenic kinase, which is required for proper functioning of Hsp90 (BachleitnerHofmann et al., 2011). FW-04-806 (Huang et al., 2015), ganetespib (Patel et al., 2014), and other Hsp90 inhibitors are believed to decrease the expression of EGFR. The results of this study also suggested that SNX-2112 induced a decrease in the expression of EGFR, which indicated the important role played by SNX-2112 in inhibiting Hsp90, via the downregulation of EGFR.

p53 plays a major role in transcription in humans and is responsible for maintaining normal cell growth, regulating apoptosis, and preventing malignant transformation in cells (Timani et al., 2015). Mutations in the $p 53$ gene could lead to decreased anticancer activity and promote malignant transformation (Bywater et al., 2012). Low expression of p53 is also associated with high response to chemotherapy-based treatment in EC (Zhang et al., 2013); for example, phospholipase $\mathrm{C}$ epsilon 1 modulates the apoptosis mechanism by suppressing p53 expression in esophageal cancer (Li et al., 2014) cells, while ECRG2 combined with cisplatin has been shown to promote apoptosis in EC cells by upregulating p53 (Song et al., 2014). This indicated that p53 is an important mediator in this complex system. In this study, we confirmed that p53 expression increased significantly with the development of EC; additionally, SNX2112 treatment was shown to induce a significant decrease in p53 expression, which indicated that SNX-2112 also played an important role in the apoptosis process by interfering with the p53 expression. To the best of our knowledge, the mechanism by which SNX-2112 affects p53 has not been documented; the results of the study suggested that this mechanism exerted a significant effect on the treatment of EC. 
Hsp90 has been shown to stimulate apoptosis and inhibition of proliferation of esophageal squamous cell cancer (ESCC) cells; moreover, SNX-2112 treatment was shown to induce a decrease in the expression of proliferating cell nuclear antigen and a corresponding increase in the number of apoptotic cells in ESCC tissues (Wang et al., 2015). SNX-2112 combined with 5-FU has an antagonistic effect on esophageal cancer cells by affecting the growth inhibition, cell cycle, and apoptosis mechanisms (Liu et al., 2015). We further confirmed that SNX-2112 inhibits the proliferation of EC-9706 cells by regulating ERCC1, EGFR, and p53. However, the exact mechanisms remain to be explained. This could be confirmed by further studies with larger sample sizes.

In summary, ERCC1, EGFR, and p53 play an important role in the complex EC system and are potential prognostic markers for EC. Furthermore, SNX-2112 inhibits the proliferation of esophageal cancer cells by regulating the expression of ERCC1, EGFR, and p53.

\title{
Conflicts of interest
}

The authors declare no conflict of interest.

\section{ACKNOWLEDGMENTS}

\author{
Research supported by the Shandong Natural Foundation (Grant \#ZR2014HM061).
}

\section{REFERENCES}

Avraham R and Yarden Y (2011). Feedback regulation of EGFR signalling: decision making by early and delayed loops. Nat. Rev. Mol. Cell Biol. 12: 104-117. http://dx.doi.org/10.1038/nrm3048

Bachleitner-Hofmann T, Sun MY, Chen CT, Liska D, et al. (2011). Antitumor activity of SNX-2112, a synthetic heat shock protein-90 inhibitor, in MET-amplified tumor cells with or without resistance to selective MET Inhibition. Clin. Cancer Res. 17: 122-133. http://dx.doi.org/10.1158/1078-0432.CCR-10-0253

Bastid J (2012). EMT in carcinoma progression and dissemination: facts, unanswered questions, and clinical considerations. Cancer Metastasis Rev. 31: 277-283. http://dx.doi.org/10.1007/s10555-011-9344-6

Belkhiri A and El-Rifai W (2015). Advances in targeted therapies and new promising targets in esophageal cancer. Oncotarget 6: 1348-1358. http://dx.doi.org/10.18632/oncotarget.2752

Bywater MJ, Poortinga G, Sanij E, Hein N, et al. (2012). Inhibition of RNA polymerase I as a therapeutic strategy to promote cancer-specific activation of p53. Cancer Cell 22: 51-65. http://dx.doi.org/10.1016/j.ccr.2012.05.019

Calderón-Montaño JM, Burgos-Morón E, Orta ML and López-Lázaro M (2014). Effect of DNA repair deficiencies on the cytotoxicity of drugs used in cancer therapy - a review. Curr. Med. Chem. 21: 3419-3454. http://dx.doi.org/10.2174 $\underline{10929867321666140601203816}$

Chen CY, Yang SC, Lee KH, Yang X, et al. (2014). The antitumor agent PBT-1 directly targets HSP90 and hnRNP A2/B1 and inhibits lung adenocarcinoma growth and metastasis. J. Med. Chem. 57: 677-685. http://dx.doi.org/10.1021/jm401686b

Chen D, Frezza M, Schmitt S, Kanwar J, et al. (2011). Bortezomib as the first proteasome inhibitor anticancer drug: current status and future perspectives. Curr. Cancer Drug Targets 11: 239-253. http://dx.doi. org/10.2174/156800911794519752

Doll CM, Prystajecky M, Eliasziw M, Klimowicz AC, et al. (2010). Low ERCC1 mRNA and protein expression are associated with worse survival in cervical cancer patients treated with radiation alone. Radiother. Oncol. 97: 352359. http://dx.doi.org/10.1016/j.radonc.2010.08.019

Fan Y, Zou W, Green LA, Kim BO, et al. (2011). Activation of Egr-1 expression in astrocytes by HIV-1 Tat: new insights into astrocyte-mediated Tat neurotoxicity. J. Neuroimmune Pharmacol. 6: 121-129. http://dx.doi.org/10.1007/s11481-010-9217-8

Goldstein M and Kastan MB (2015). The DNA damage response: implications for tumor responses to radiation and chemotherapy. Аnпu. Rev. Med. 66: 129-143. http://dx.doi.org/10.1146/annurev-med-081313-121208

Hall JA, Kusuma BR, Brandt GE and Blagg BS (2014). Cruentaren A binds F1F0 ATP synthase to modulate the Hsp90 protein folding machinery. ACS Chem. Biol. 9: 976-985. http://dx.doi.org/10.1021/cb400906e

Holohan C, Van Schaeybroeck S, Longley DB and Johnston PG (2013). Cancer drug resistance: an evolving paradigm. 
Nat. Rev. Cancer 13: 714-726. http://dx.doi.org/10.1038/nrc3599

Huang W, Wu QD, Zhang M, Kong YL, et al. (2015). Novel Hsp90 inhibitor FW-04-806 displays potent antitumor effects in HER2-positive breast cancer cells as a single agent or in combination with lapatinib. Cancer Lett. 356 (2 Pt B): 862-871. http://dx.doi.org/10.1016/j.canlet.2014.10.040

Johnson ML, Yu HA, Hart EM, Weitner BB, et al. (2015). Phase I/II study of HSP90 inhibitor AUY922 and erlotinib for EGFR-mutant lung cancer with acquired resistance to epidermal growth factor receptor tyrosine kinase inhibitors. $J$. Clin. Oncol. 33: 1666-1673. http://dx.doi.org/10.1200/JCO.2014.59.7328

Kaz AM and Grady WM (2014). Epigenetic biomarkers in esophageal cancer. Cancer Lett. 342: 193-199. http://dx.doi. org/10.1016/j.canlet.2012.02.036

Kim MK, Cho KJ, Kwon GY, Park SI, et al. (2008). ERCC1 predicting chemoradiation resistance and poor outcome in oesophageal cancer. Eur. J. Cancer 44: 54-60.

Li M, Zhang X, Zhou WJ, Chen YH, et al. (2013). Hsp90 inhibitor BIIB021 enhances triptolide-induced apoptosis of human T-cell acute lymphoblastic leukemia cells in vitro mainly by disrupting p53-MDM2 balance. Acta Pharmacol. Sin. 34: 1545-1553. http://dx.doi.org/10.1038/aps.2013.124

Li Y, An J, Huang S, Liao H, et al. (2014). PLCE1 suppresses p53 expression in esophageal cancer cells. Cancer Invest. 32: 236-240. http://dx.doi.org/10.3109/07357907.2014.905588

Liu Y, Wang X, Wang Y, Zhang Y, et al. (2015). Combination of SNX-2112 with 5-FU exhibits antagonistic effect in esophageal cancer cells. Int. J. Oncol. 46: 299-307.

Lopez-Serra P and Esteller M (2012). DNA methylation-associated silencing of tumor-suppressor microRNAs in cancer. Oncogene 31: 1609-1622. http://dx.doi.org/10.1038/onc.2011.354

Mohamed A, El-Rayes B, Khuri FR and Saba NF (2014). Targeted therapies in metastatic esophageal cancer: advances over the past decade. Crit. Rev. Oncol. Hematol. 91: 186-196. http://dx.doi.org/10.1016/j.critrevonc.2014.01.010

Patel K, Wen J, Magliocca K, Muller S, et al. (2014). Heat shock protein 90 (HSP90) is overexpressed in p16-negative oropharyngeal squamous cell carcinoma, and its inhibition in vitro potentiates the effects of chemoradiation. Cancer Chemother. Pharmacol. 74: 1015-1022. http://dx.doi.org/10.1007/s00280-014-2584-8

Pennathur A, Gibson MK, Jobe BA and Luketich JD (2013). Oesophageal carcinoma. Lancet 381: 400-412. http://dx.doi. org/10.1016/S0140-6736(12)60643-6

Rahman MA, Salajegheh A, Smith RA and Lam AK (2014). BRAF inhibitor therapy for melanoma, thyroid and colorectal cancers: development of resistance and future prospects. Curr. Cancer Drug Targets 14: 128-143. http://dx.doi.org/ $\underline{10.2174 / 1568009614666140121150930}$

Rivlin N, Brosh R, Oren M and Rotter V (2011). Mutations in the p53 tumor suppressor gene: important milestones at the various steps of tumorigenesis. Genes Cancer 2: 466-474. http://dx.doi.org/10.1177/1947601911408889

Song HY, Deng XH, Yuan GY, Hou XF, et al. (2014). Expression of bcl-2 and p53 in induction of esophageal cancer cell apoptosis by ECRG2 in combination with cisplatin. Asian Pac. J. Cancer Prev. 15: 1397-1401. http://dx.doi. org/10.7314/APJCP.2014.15.3.1397

Taipale M, Krykbaeva I, Koeva M, Kayatekin C, et al. (2012). Quantitative analysis of HSP90-client interactions reveals principles of substrate recognition. Cell 150: 987-1001. http://dx.doi.org/10.1016/j.cell.2012.06.047

Timani KA, Liu Y, Fan Y, Mohammad KS, et al. (2015). Tip110 regulates the cross talk between p53 and hypoxiainducible factor 1alpha under hypoxia and promotes survival of cancer cells. Mol. Cell. Biol. 35: 2254-2264. http:// dx.doi.org/10.1128/MCB.00001-15

Tong Z, Fan Y, Zhang W, Xu J, et al. (2009). Pancreas-specific Pten deficiency causes partial resistance to diabetes and elevated hepatic AKT signaling. Cell Res. 19: 710-719. http://dx.doi.org/10.1038/cr.2009.42

Tsai MS, Weng SH, Chen HJ, Chiu YF, et al. (2012). Inhibition of p38 MAPK-dependent excision repair crosscomplementing 1 expression decreases the DNA repair capacity to sensitize lung cancer cells to etoposide. Mol. Cancer Ther. 11: 561-571. http://dx.doi.org/10.1158/1535-7163.MCT-11-0684

Wang S, Du Z, Luo J, Wang X, et al. (2015). Inhibition of heat shock protein 90 suppresses squamous carcinogenic progression in a mouse model of esophageal cancer. J. Cancer Res. Clin. Oncol. 141: 1405-1416. http://dx.doi. org/10.1007/s00432-014-1896-8

Worster DT, Schmelzle T, Solimini NL, Lightcap ES, et al. (2012). Akt and ERK control the proliferative response of mammary epithelial cells to the growth factors IGF-1 and EGF through the cell cycle inhibitor p57Kip2. Sci. Signal. 5: ra19. http://dx.doi.org/10.1126/scisignal.2001986

Zhang SS, Huang QY, Yang H, Xie X, et al. (2013). Correlation of p53 status with the response to chemotherapy-based treatment in esophageal cancer: a meta-analysis. Ann. Surg. Oncol. 20: 2419-2427. http://dx.doi.org/10.1245/s10434-012-2859-4

Zhen Y, Guanghui L and Xiefu Z (2014). Knockdown of EGFR inhibits growth and invasion of gastric cancer cells. Cancer Gene Ther. 21: 491-497. http://dx.doi.org/10.1038/cgt.2014.55 